\title{
CFD simulation of pollutant dispersion around isolated buildings: on the role of convective and turbulent mass fluxes in the prediction accuracy
}

\author{
P. Gousseau* (a) ${ }^{*}$ B. Blocken ${ }^{(b)}$, G.J.F. van Heijst ${ }^{(c)}$ \\ (a) Building Physics and Systems, Eindhoven University of Technology, P.O. Box 513, 5600 MB Eindhoven, \\ The Netherlands, p.gousseau@tue.nl \\ (b) Building Physics and Systems, Eindhoven University of Technology, P.O. Box 513, 5600 MB Eindhoven, \\ The Netherlands, b.j.e.blocken@tue.nl \\ (c) Fluid Dynamics Laboratory, Department of Physics, Eindhoven University of Technology, P.O. Box 513, \\ 5600 MB Eindhoven, The Netherlands, g.j.f.v.heijst@tue.nl
}

\begin{abstract}
Computational Fluid Dynamics (CFD) is increasingly used to predict wind flow and pollutant dispersion around buildings. The two most frequently used approaches are solving the Reynoldsaveraged Navier-Stokes (RANS) equations and Large-Eddy Simulation (LES). In the present study, we compare the convective and turbulent mass fluxes predicted by these two approaches for two configurations of isolated buildings with distinctive features. We use this analysis to clarify the role of these two components of mass transport on the prediction accuracy of RANS and LES in terms of mean concentration. It is shown that the proper simulation of the convective fluxes is essential to predict an accurate concentration field. In addition, appropriate parameterization of the turbulent fluxes is needed with RANS models, while only the subgrid-scale effects are modeled with LES. Therefore, when the source is located outside of recirculation regions (case 1), both RANS and LES can provide accurate results. When the influence of the building is higher (case 2), RANS models predict erroneous convective fluxes and are largely outperformed by LES in terms of prediction accuracy of mean concentration. These conclusions suggest that the choice of the appropriate turbulence model depends on the configuration of the dispersion problem under study. It is also shown that for both cases LES predicts a counter-gradient mechanism of the streamwise turbulent mass transport, which is not reproduced by the gradient-diffusion hypothesis that is generally used with RANS models.
\end{abstract}

Keywords: Convective flux; turbulent flux; urban wind flow; turbulence modeling; gas dispersion.

\section{Introduction}

Computational Fluid Dynamics (CFD) is increasingly explored and used to predict wind flow and pollutant dispersion around buildings. Accurate numerical simulation of this complex coupled process requires careful simulation of each of its constituents: (1) the incoming Atmospheric Boundary Layer (ABL) flow; (2) the turbulent wind flow around the buildings submerged in the ABL; and (3) the transport process of the pollutant by convection and diffusion in the turbulent wind-flow pattern. Because of the turbulent and inherently transient nature of the flow around buildings, the accuracy of pollutant dispersion simulations is strongly influenced by the turbulence modeling approach used, which is generally either steady Reynolds-Averaged Navier-Stokes (RANS) or Large-Eddy Simulation (LES).

In turbulent flows, dispersion can be seen as the combination of the molecular, convective and turbulent mass transport, where the first is often negligibly small compared with the two others. Several earlier research efforts have compared the performance of RANS and LES approaches for pollutant dispersion in idealized urban geometries like street canyons (e.g. $[1,2,3,4])$ and arrays of

* Corresponding author: Pierre Gousseau, Building Physics and Systems, Eindhoven University of Technology, P.O. Box 513, 5600 MB Eindhoven, The Netherlands. Tel: +31 (0)40 247 4374. Fax: +31 (0)40 2438595

E-mail address: p.gousseau@tue.nl 
buildings (e.g. [5,6]). Other efforts have compared RANS and LES for isolated buildings (e.g. [7,8]), or in real urban environments (e.g. [9,10]). Overall, LES appears to be more accurate than RANS in predicting the mean concentration field because it captures the unsteady concentration fluctuations. Moreover, this approach provides the statistics of the concentration field which can be of prime importance for practical applications.

Most of the aforementioned studies have analyzed the prediction accuracy of CFD by comparing the resulting mean concentrations on and around building surfaces. Only few of them have analyzed the performance of RANS and LES by focusing on the mass transport process itself. Tominaga and Stathopoulos [3] compared the lateral and vertical turbulent fluxes inside a street canyon computed with RANS and LES. Yoshie et al. [8] employed these two approaches to illustrate the horizontal distribution of the lateral turbulent mass flux around an isolated building with non-isothermal ABL flow. Rossi et al. [11] compared the performance of different turbulent flux models for RANS for dispersion around a cube. Direct Numerical Simulation was also performed for a uniform inflow profile and a Reynolds number equal to 5,000. To the best of our knowledge, only Tominaga and Stathopoulos [7] provided some information about convective and diffusive fluxes for the case of dispersion around a building in an ABL flow, but their study focused at only a few locations on the roof.

In this paper, we present a detailed analysis of the transport process of a pollutant in the turbulent wind-flow pattern around isolated buildings. The relative influence of convective and turbulent fluxes in the transport process is analyzed and the role of these fluxes in the prediction accuracy of RANS and LES simulations is clarified. For this purpose, two cases with distinctive features in terms of the transport process are selected, for which also detailed wind tunnel experiments are available:

1. Dispersion from a stack located immediately downstream of an isolated rectangular building [12];

2. Dispersion from a rooftop vent on an isolated cubical building [13].

In case 1, the stack is relatively high and discharges the pollutants outside the building wake, which decreases the influence of the building on the dispersion of the plume. In case 2, the source is located directly on the roof of the building and the pollutant gas is released with low momentum ratio into the rooftop separation bubble. Validation of the CFD simulations is performed by comparing the numerical results with the wind-tunnel concentration measurements presented in $[12,13]$. For case 1, concentration profiles along three lines located five building heights downstream of the building are used whereas for case 2, concentration contours on the roof and in the wake of the building are used.

Some details about the numerical procedure are given in the next section. Then, for each case, the experiment is outlined, the numerical model is described and the results are presented and analyzed.

\section{Governing equations}

\subsection{RANS and turbulence models}

With the RANS approach, the Reynolds-averaging operator is applied to the flow equations. Only the averaged quantities are computed and the effect of turbulence on the average flow field symbolized by the Reynolds stresses- is modeled with turbulence models. In this study, four turbulence models will be used and compared: the standard k- $\varepsilon$ model (SKE) [14], the realizable k- $\varepsilon$ model (RLZ) [15], the renormalization-group (RNG) k- $\varepsilon$ model [16], and the Reynolds-Stress model (RSM) with a linear pressure-strain model and wall-reflection effects $[17,18]$. The relevant equations can be found in the references. For brevity, only the model constants are given here. They are the default values in Fluent 6.3. For SKE: $\mathrm{C}_{\mu}=0.09 ; \mathrm{C}_{1 \varepsilon}=1.44 ; \mathrm{C}_{2 \varepsilon}=1.9 ; \sigma_{\mathrm{k}}=1.0 ; \sigma_{\varepsilon}=1.3$. For RLZ: $\mathrm{C}_{1 \varepsilon}=1.44 ; \mathrm{C}_{2 \varepsilon}=1.9 ; \sigma_{\mathrm{k}}=1.0 ; \sigma_{\varepsilon}=1.2$. For RNG: $\mathrm{C}_{\mu}=0.0845 ; \mathrm{C}_{1 \varepsilon}=1.42 ; \mathrm{C}_{2 \varepsilon}=1.68$. For RSM: $\mathrm{C}_{\mu}=0.09$; $\mathrm{C}_{1 \varepsilon}=1.44 ; \mathrm{C}_{2 \varepsilon}=1.92 ; \mathrm{C}_{1}=1.8 ; \mathrm{C}_{2}=0.6 ; \mathrm{C}^{\prime}{ }_{1}=0.5 ; \mathrm{C}_{2}{ }_{2}=0.3 ; \sigma_{\mathrm{k}}=1.0 ; \sigma_{\varepsilon}=1.3$.

\subsection{LES and subgrid-scale models}

With LES, a spatial-filtering operator is applied to the Navier-Stokes equations to separate the smallest scales of motion, which have a more universal behavior and can therefore be modeled, and the large scales, which are explicitly resolved. The effect of the smallest scales on the resolved flow 
field is modeled with a subgrid-scale (SGS) model. In this study, the dynamic Smagorinsky SGS model $[19,20,21]$ is used. LES is particularly interesting when dealing with mass transport phenomena since this process is mainly governed by the largest scales of motion.

\subsection{Numerical procedure}

For the RANS simulations presented here, all the transport equations (momentum, energy, $\mathrm{k}, \varepsilon$ and concentration) are discretized using a second-order upwind scheme. Pressure interpolation is second order. The SIMPLE algorithm is used for pressure-velocity coupling. Convergence is assumed to be obtained when the scaled residuals [22] reach $10^{-5}$.

For LES, the filtered momentum equation is discretized with a bounded central-differencing scheme. A second-order upwind scheme is used for the energy and concentration equations. Pressure interpolation is second order. Time integration is second-order implicit. The non-iterative fractional step method [23] is used for time advancement.

\subsection{Wall treatment}

In order to properly simulate the approaching ABL flow in the computational domain, horizontal homogeneity must be achieved, i.e. the vertical flow profiles that are prescribed at the inlet must be preserved along the domain before reaching the buildings [24,25].

For RANS simulations with the Fluent 6.3 CFD code, the standard wall functions [26] are applied to the wall boundaries (ground, building and stack surfaces). For the ground, the wall functions are modified for roughness [27], which is specified by an equivalent sand-grain roughness height $\mathrm{k}_{\mathrm{s}}$ and a roughness constant $\mathrm{C}_{\mathrm{r}}$. Horizontal inhomogeneity of the $\mathrm{ABL}$ can be limited by adapting $\mathrm{k}_{\mathrm{S}}$ and $\mathrm{C}_{\mathrm{r}}$ to the inlet ABL profiles, following the equation by Blocken et al. [24]: $k_{s}=9.793 z_{0} / C_{r}$, where $z_{0}$ is the aerodynamic roughness length of the terrain.

To the authors' best knowledge, such a relation does not exist for LES with Fluent. In this case, the centroids of the wall-adjacent cells are assumed to fall in the logarithmic-law region of the boundary layer [22] and the wall roughness is not taken into account. The same boundary condition is used for the smooth walls, i.e. the building and stack surfaces.

In both RANS and LES simulations, the upstream domain length is kept as short as possible $(5 \mathrm{H})$ to limit horizontal inhomogeneity [24]. A posteriori verification showed that the maximum wallnormal distance of the first centroid at the wall boundaries was approximately 100 wall units $\left(\mathrm{z}^{+}=\mathrm{zu} * / \mathrm{v}\right.$, where $\mathrm{z}$ is the wall-normal distance, $\mathrm{u}^{*}$ is the friction velocity and $v$ is the kinematic viscosity of the fluid) for case 1 and 40 for case 2 .

\subsection{Dispersion modeling}

The instantaneous pollutant concentration $\left(\mathrm{c}\left[\mathrm{kg} \cdot \mathrm{m}^{-3}\right]\right)$ is treated as a scalar transported by an advection-diffusion equation (Eulerian approach):

$$
\frac{\partial c}{\partial t}+\vec{u} \cdot \nabla c=-\nabla \cdot \overrightarrow{q_{m}}+s_{c}
$$

where $\overrightarrow{\mathrm{u}}$ is the velocity vector; $\mathrm{s}_{\mathrm{c}}$ is a source term; and $\overrightarrow{\mathrm{q}_{\mathrm{m}}}$ is the mass flux due to molecular diffusion.

Applying the Reynolds decomposition to the variables ( $\mathrm{x}=\mathrm{X}+\mathrm{x}$ ' where $\mathrm{X}=<\mathrm{x}>$ and $\mathrm{x}$ ' are the mean and fluctuating components of $\mathrm{x}$, respectively) and averaging Eq. 6 yields:

$$
\nabla \cdot\left(\overrightarrow{Q_{m}}+\overrightarrow{Q_{c}}+\overrightarrow{Q_{t}}\right)=S_{c}
$$

In this equation, $\overrightarrow{\mathrm{Q}_{\mathrm{m}}}$ is the mean molecular mass flux $\left[\mathrm{kg} \cdot \mathrm{m}^{-2} \cdot \mathrm{s}^{-1}\right]$, proportional to the gradient of mean concentration:

$$
Q_{m, i}=-D_{m} \frac{\partial C}{\partial x_{i}}
$$


where $D_{m}$ is the molecular mass diffusivity $\left[\mathrm{m}^{2} \cdot \mathrm{s}^{-1}\right]$. In general, the molecular mass flux is negligible in comparison with the mean convective (the adjective "mean" will be omitted in what follows) and

turbulent mass fluxes, symbolized by $\overrightarrow{Q_{c}}$ and $\overrightarrow{Q_{t}}$, respectively. The former corresponds to the advection of the mean concentration by the mean flow; it is defined by:

$Q_{c, i}=U_{i} C$

The turbulent mass flux is given by:

$Q_{t, i}=<u_{i}^{\prime} c^{\prime}>$

Neither the velocity nor the concentration fluctuations are computed by the RANS models so, with this approach, the turbulent flux must be linked to the mean variables. Generally, the gradient-diffusion hypothesis is adopted, by analogy with molecular diffusion:

$Q_{t, i, R A N S}=-D_{t} \frac{\partial C}{\partial x_{i}}$

where $D_{t}$ is the turbulent mass diffusivity whose value is deduced from the computed turbulent viscosity $v_{t}$ and the input value of the turbulent $S c h m i d t$ number $S c_{t}=v_{t} / D_{t}$. This parameter is known to have a large influence on the simulation of dispersion, with an optimum value that strongly depends on the configuration under study $[28,29]$.

With LES, the effect of the smallest scales of motion on dispersion is modeled by the SGS mass flux $\overrightarrow{\mathrm{q}_{\mathrm{sgs}}}$ that appears in the filtered dispersion equation:

$q_{s g s, i}=\overline{u_{i} c}-\overline{u_{i} c}=-D_{s g s} \frac{\partial \bar{c}}{\partial x_{i}}$

where the overbar denotes the filtering operation and $\mathrm{D}_{\mathrm{sgs}}$ is the SGS mass diffusivity computed via the SGS viscosity $v_{\mathrm{sgs}}$ and the SGS Schmidt number $\mathrm{Sc}_{\mathrm{sgs}}=v_{\mathrm{sg}} / \mathrm{D}_{\mathrm{sgg}}$. Here, $\mathrm{Sc}_{\mathrm{sgs}}$ is computed dynamically, with a similar procedure as the Smagorinsky coefficient $C_{s}$ [30]. In the LES results presented here, the convective and turbulent fluxes are computed based on the resolved variables:

$Q_{c, i, L E S}=<\overline{u_{i}}><\bar{c}>$

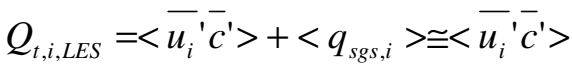

The subscript "LES" will be omitted in what follows, as well as the subscript "RANS" in Eq. 11. The mean SGS mass flux $<\mathrm{q}_{\mathrm{sgs}, \mathrm{i}}>$ is neglected in the computation of the turbulent mass flux (Eq. 14): in the two cases considered here it is generally one or two orders of magnitude lower than $\left\langle\overline{\mathrm{u}}_{\mathrm{i}}{ }^{\prime} \overline{\mathrm{c}}{ }^{\prime}\right\rangle$.

All concentrations are expressed in non-dimensional form. The instantaneous concentration coefficient is defined by:

$$
K_{\text {inst }}=\frac{c}{C_{0}}
$$

where $\mathrm{C}_{0}$ is the reference concentration $\left[\mathrm{kg} \cdot \mathrm{m}^{-3}\right]$ given by:

$C_{0}=\frac{Q_{e}}{H^{2} U_{r e f}}$

with $\mathrm{Q}_{\mathrm{e}}$ the pollutant exhaust rate $\left[\mathrm{kg} \cdot \mathrm{s}^{-1}\right] ; \mathrm{H}$ the building height and $\mathrm{U}_{\text {ref }}$ the mean wind speed at reference height $\mathrm{z}_{\mathrm{ref}}\left(\mathrm{z}_{\mathrm{ref}}=1.5 \mathrm{H}\right.$ for case $1 ; \mathrm{z}_{\text {ref }}=\mathrm{H}$ for case 2$)$. The mean non-dimensional concentration coefficient $\mathrm{K}$ is defined as the average value of $\mathrm{K}_{\text {inst }}$. A reference flux magnitude $\mathrm{Q}_{0}=\mathrm{C}_{0} \mathrm{U}_{\text {ref }}$ is used to make the convective and turbulent mass fluxes non-dimensional.

\section{Case 1: dispersion from a stack downstream of an isolated rectangular building}

\subsection{Description of the experiment}

Huber et al. [12] performed detailed experiments of gas dispersion around a rectangular building model in a wind tunnel. The building dimensions are $\mathrm{H} \times 2 \mathrm{H} \times \mathrm{H}$ in the longitudinal (x), lateral (y) and vertical (z) directions, respectively, where $\mathrm{H}=0.25 \mathrm{~m}$. An ABL flow is simulated in the wind tunnel, with a Reynolds number based on $U_{\text {ref }}$ and $z_{\text {ref }}(R e)$ equal to $6.0 \times 10^{4}$ and with $z_{0}=6.5 \times 10^{-4} \mathrm{~m}$ at model 
scale (1:200). Immediately downstream of the building, a stack of height $1.5 \mathrm{H}$ and diameter $0.042 \mathrm{H}$ is emitting a mixture of air and methane with a momentum ratio $(\mathrm{M})$ equal to 1.5 . $\mathrm{M}$ is defined as the ratio $\mathrm{W}_{\mathrm{e}} / \mathrm{U}_{\text {ref }}$ where $\mathrm{W}_{\mathrm{e}}$ is the vertical exhaust velocity. The origin of the coordinate system is shown in Fig. 1a.

Experimental data used to validate the present simulations are the profiles of $\mathrm{K}$ along three lines 5H downstream of the source (Fig. 1a): H5-0 and H5-1.5 are horizontal lines located at ground $(\mathrm{z} / \mathrm{H}=0.1)$ and stack $(\mathrm{z} / \mathrm{H}=1.5)$ level, respectively, and V5 is a vertical line in the mid-plane $(\mathrm{y} / \mathrm{H}=0)$. It should be stressed that the conclusions drawn here on the performance of each turbulence model hold for this particular location. The results are indeed quite different closer to the building (see case 2) or farther downstream, where the accurate simulation of the ABL is crucial.

\subsection{Domain, computational grid and boundary conditions}

The domain dimensions follow the COST 732 and AIJ guidelines [31,32]: $26 \mathrm{H}$ (length) $\times 14 \mathrm{H}$ (width) $\times 7 \mathrm{H}$ (height), based on the model scale. An upstream length of $5 \mathrm{H}$ and a downstream length of $20 \mathrm{H}$ are provided to place the boundaries out of the zone of influence of the building (Fig. 1a).

RANS and LES computations are performed on the same computational grid composed of $1,450,960$ prismatic cells and constructed using the surface-grid extrusion procedure [33]. The growth ratio of adjacent cells does not exceed 1.1. The building height and the stack circumference are divided into 20 and 64 cells, respectively (Fig. 1b). A grid-sensitivity analysis showed that grid refinement did not lead to significant change in the concentration results.

The inlet profiles of $\mathrm{U}_{\mathrm{in}}, \mathrm{k}$ and $\varepsilon$ are based on the wind-tunnel measurements reported in [12]. At the outlet, zero static pressure is prescribed. At the top and lateral boundaries, a symmetry boundary condition is imposed. The bottom boundary as well as the building and stack surfaces are defined as no-slip walls; wall treatment is set as described in section 2.4. A velocity inlet is defined at the top face of the stack, with an assumed turbulence intensity of $10 \%$ and a methane volume fraction of $1 \%$, as in the experiment.

For the LES computations, a time-dependent inlet profile is generated by using the vortex method [34] with a number of vortices $N_{v}=190$. As shown by Sergent [34], this parameter has only little influence on the generated velocity fluctuations. Furthermore, previous CFD simulations of air flow around a cube (not presented here) have shown that this method is suitable to generate turbulent fluctuations at the inlet in the case of ABL flow around a bluff body. The results of the LES computation presented here are averaged over a period of 312 non-dimensional time units $\left(t^{*}=t \times U_{\text {ref }} / z_{\text {ref }}\right)$ with a constant non-dimensional time step $\Delta t^{*}=\Delta t \times U_{\text {ref }} / Z_{\text {ref }}=0.062$. It was verified that the averaging time is sufficient to obtain statistically-steady results by monitoring the evolution of $\mathrm{K}$ with time (moving average).

\subsection{Results}

The first three graphs of Fig. 2 (Figs. 2a,b,c) show the influence of $\mathrm{Sc}_{\mathrm{t}}$ on the concentration values obtained with RLZ 5H downstream of the building model. For the three measurement lines, RLZ can predict K-values in close agreement with the experiments when $\mathrm{Sc}_{\mathrm{t}}$ is set to 0.5. A lower (resp. higher) value of $\mathrm{Sc}_{\mathrm{t}}$ leads to an under- (resp. over-) estimation of the concentration values along lines H5-1.5 and V5. The sensitivity to $\mathrm{Sc}_{\mathrm{t}}$ is lower on line H5-0 (Fig. 2a) because, close to the ground, turbulent mass transport -which is governed by this parameter- is limited by the presence of the wall.

The other RANS models have been tested with $\mathrm{Sc}_{\mathrm{t}}=0.5$ (Figs. 2d,e,f). For this case, the difference between SKE and RLZ results is negligible. RSM also provides accurate results, with a slight overestimation of $\mathrm{K}$ in comparison with the measurements. RNG largely overestimates the concentration and should be used here with a lower $\mathrm{Sc}_{\mathrm{t}}$ value. On line $\mathrm{H} 5-0$, the computed variables depend more on the wall treatment than on the turbulence model itself, explaining why the difference between the RANS models is low (Fig. 2d).

The average LES results agree fairly well with the experiment on the three measurement lines. Fig. $2 \mathrm{i}$ shows that, contrary to RANS models which compute the local maximum of concentration at the level of the stack $(\mathrm{z} / \mathrm{H}=1.5)$, LES predicts that the centerline of the plume is shifted downwards, in agreement with the experiment. This deviation can also be observed when looking at the average 
shape of the plume symbolized by the isosurface $K=1$ in Fig. 3. As already suggested by the concentration profiles, the plume shape is rather similar with SKE, RLZ and RSM: it extends horizontally downstream without being much disturbed by the presence of the building, whereas the isosurface computed with RNG extends farther downstream. Fig. $3 \mathrm{f}$ shows the isosurface $\mathrm{K}_{\text {inst }}=1$ at $t^{*}=312$ computed with LES. At this instant, the plume is largely different from its average shape: the region where $\mathrm{K}$ exceeds 1 can extend farther downstream and reach zones close to the ground.

The non-dimensional convective and turbulent mass fluxes are depicted in Figs. 4 and 5, respectively. Because of the similarity between SKE and RLZ results, it has been chosen to show only the fluxes computed by the latter model for sake of brevity. The emitted pollutant gas is mainly convected downstream, as shown by the contours of convective flux in the streamwise direction (Figs. $4 \mathrm{a}, \mathrm{c}, \mathrm{e}, \mathrm{g})$. In these figures, the blue/dark gray zone downstream of the building indicates the backflow of the wake recirculation zone, whose length is largely overestimated by the RANS models in comparison with LES. However, since only little pollution reaches this zone, the magnitude of the flux is low and only marginally influences the final concentration field.

The vertical exhaust velocity from the stack creates a positive $\mathrm{Q}_{c, z}$ around this position (Figs $4 \mathrm{~b}, \mathrm{~d}, \mathrm{f}, \mathrm{h})$. Further downstream, the negative vertical velocity due to flow reattachment transports the pollutant towards the ground. Fig. 4h shows that with LES, this downward convective flux occurs closer to the building -due to the smaller recirculation zone- and is more intense than with the RANS models. As a consequence, the centerline of the plume is deviated downwards, as already observed in the previous figures and in agreement to what was measured in the wind tunnel.

In this case, the main difference between the mass fluxes computed by RANS and LES approaches lies in the streamwise turbulent flux $\mathrm{Q}_{\mathrm{t}, \mathrm{x}}$, shown in Figs. 5a,c,e,g. Let us consider the concentration level at stack height. Following the gradient-diffusion hypothesis (Eq. 11), the decrease of the concentration in the $\mathrm{x}$-direction $(\partial \mathrm{C} / \partial \mathrm{x}<0)$ generates a positive flux, represented in red/light gray in Figs. 5a,c,e. Although the evolution of $\mathrm{C}$ is similar with LES, it is clear that the turbulent mass transport in this direction does not obey the gradient-diffusion hypothesis: $\mathrm{Q}_{\mathrm{t}, \mathrm{x}}$ is negative and counters convective effects in the region above the stack $(\mathrm{z} / \mathrm{H}>1.5)$ and it is positive below the stack for $\mathrm{x} / \mathrm{H}>1$ (Fig. 5g). It can also be noted that the values of $\left|\mathrm{Q}_{\mathrm{t}, \mathrm{x}} / \mathrm{Q}_{0}\right|$ computed by LES are higher than with RANS. However, by comparing the left column of Fig. 4 with the one of Fig. 5 (the same contour levels are used for both figures), it is clear that the main mechanism of mass transport in the streamwise direction is convection. Hence, the deficiencies of the RANS models -and more particularly of the gradient-diffusion hypothesis- in terms of streamwise turbulent transport do not significantly affect the final concentration field. This explains why fairly accurate results can be obtained with these models and hypothesis.

The balance between convective and turbulent mass transport is different in the vertical direction: the comparison of the right columns of Figs. 4 and 5 shows that both mechanisms act with similar intensity. Turbulent vertical fluxes are even stronger, except in the near wake of the building and at the plume centerline. The roles of these mechanisms are different, however: while convection tends to act on the plume as a "block" (i.e. by moving its centerline), turbulence tends to "stretch" the plume in the vertical (and lateral) direction. Indeed, it was already observed in Fig. 2b, for instance, that if $\mathrm{Sc}_{\mathrm{t}}$ is decreased (i.e. $\mathrm{Q}_{\mathrm{t}, \mathrm{z}}$ is increased), the stretching effect becomes stronger in the vertical and lateral directions. Both RANS (Figs. 5b,d,f) and LES (Fig. 5h) models predict a similar trend for the contours of $\mathrm{Q}_{\mathrm{t}, \mathrm{Z}} / \mathrm{Q}_{0}$, which supports the validity of the gradient-diffusion hypothesis in the vertical direction. This also holds for the lateral direction (not shown here).

\section{Case 2: dispersion from a rooftop vent on an isolated cubical building}

\subsection{Description of the experiment}

The experiment by Li and Meroney [13] involves a cubic obstacle with height $\mathrm{H}=0.05 \mathrm{~m}$ placed in the test section of a wind tunnel, with the windward face perpendicular to the ABL flow $\left(\mathrm{Re}=1.1 \times 10^{4}\right.$; $\mathrm{z}_{0}=7.5 \times 10^{-5} \mathrm{~m}$ at model scale 1:2000). At the center of the roof, pure helium is emitted by a circular exhaust with relatively low velocity $(\mathrm{M}=0.19)$. Concentration contours on the top face of the cube and in the vertical mid-plane $(\mathrm{y} / \mathrm{H}=0)$ downstream of the cube are presented here for CFD validation contrary to case 1 where line profiles were used. 


\subsection{Domain, computational grid and boundary conditions}

The domain is $26 \mathrm{H}$ long $(5 \mathrm{H}$ upstream and $20 \mathrm{H}$ downstream of the cube), $11 \mathrm{H}$ wide and $6 \mathrm{H}$ high (Fig. $6 a)$ with the origin of the coordinate system at the center of the cube's bottom face. The computational grid consists of 1,480,754 cells with 40 segments around the exhaust circumference (Fig. 6b). The cube was discretized using 25 cells in the horizontal directions and 32 cells in the vertical direction in order to increase resolution close to the roof where high concentration gradients occur. The ratio of two neighboring cell dimensions was kept below 1.1. This grid was selected after a grid-sensitivity analysis: the accuracy of the results was improved in comparison with a coarser grid and the use of a finer grid with twice the total number of cells lead to identical results with the RANS models and only a slight change in the LES concentration contours -since this model is by definition grid-dependent. However, we argue that this change did not justify the increase in computational resources required.

The profiles of $\mathrm{U}_{\mathrm{in}}, \mathrm{k}$ and $\varepsilon$ were imposed at the inlet, based on the experimental data. For LES, perturbations around the average velocity profile were imposed with the vortex method $\left(\mathrm{N}_{\mathrm{v}}=190\right)$. The other boundary conditions are identical to those in case 1 . The LES results are averaged over $t^{*}=594$, with a constant time step $\Delta t^{*}=0.066$. Note that a longer averaging period was required to get statistically-steady results compared to case 1 , because the pollutant source is located in a zone of higher turbulence intensity.

\subsection{Results}

The measured and computed contours of $K$ on the roof of the building are shown in Fig. 7. In the experiment, because of the low momentum ratio of the exhaust, the pollutant gas gets "trapped" in the rooftop recirculation zone and is transported upstream by the backflow, as can be seen in Fig. 7a. SKE and RLZ fail to reproduce this backward transport: the emitted gas is mainly "blown away" in the wind direction. RNG and RSM are more accurate and clearly reproduce the upstream transport of the pollutant (Figs. 7d,e). Nevertheless, these two models are outperformed by LES (Fig. 7f) which predicts concentrations in good agreement with the measurements, although the lateral diffusion is slightly over-predicted. Similar conclusions about the prediction accuracy of the different models are made based on the K contours in the wake of the building (Fig. 8).

$\mathrm{The}_{\mathrm{Sc}}$ value does not strongly influence the RLZ results on the roof, as shown in Fig. 7c where the isolines $\mathrm{K}=5$ and $\mathrm{K}=50$ are plotted for $\mathrm{Sc}_{\mathrm{t}}=0.3$ and 0.7. As in case 1, the reason is that turbulent mass transport is limited by the presence of the wall. In the wake of the building, the influence of this parameter is stronger and similar to the one in case 1 (Fig. 8c): when $\mathrm{Sc}_{\mathrm{t}}$ decreases the plume becomes shorter and stretched in the vertical direction. However, changing the $\mathrm{Sc}_{\mathrm{t}}$ value cannot compensate for the RANS model deficiencies in terms of flow-field and the predicted levels of concentration remain high with RLZ, as well as with SKE. The use of RNG or RSM enhances the accuracy of the results but still LES is clearly better (Figs. 8d,e,f).

The structures of the plumes computed by RNG and RSM are similar to the one by LES, yet slightly longer (Figs. 9c,d,e). SKE and RLZ show a totally different result: only little pollutant reaches the leading edge of the roof and the zone close to the ground downstream of the building is contaminated in the sense that $\mathrm{K}>1$. This is not the case with LES although some puffs of pollutant can reach this zone intermittently (Fig. 9f).

Several numerical simulations of air flow around a bluff body (e.g. [35,36,37]) have demonstrated the superior performance of LES with respect to RANS in properly simulating several features of such a flow, including the rooftop and wake recirculation zones. This difference is verified in the present study: see Figs. 10a,c,e,g, where these two backflow regions lead to an upstream mass transport (blue/dark gray zones in the contour plots of $\mathrm{Q}_{c, x} / \mathrm{Q}_{0}$ ) while pollutant is convected downstream in the rest of the domain. The rooftop recirculation zone is almost nonexistent with RLZ whereas its size is over-predicted by RNG and RSM compared with LES, with consequences on the concentration contours as already observed in Fig. 7. It can also be seen in Fig. 10 that the reattachment length in the wake is overestimated by the RANS models (due to the underestimation of $\mathrm{k}$ ), which partly explains the higher levels of concentration observed in Fig. 8. Like in case 1, this flow reattachment is responsible for a downward convective mass flux (Figs. 10b,d,f,h). 
It must be emphasized that, contrary to case 1, these recirculation regions are colored in dark blue/gray when plotting the contours of $\mathrm{Q}_{c, x} / \mathrm{Q}_{0}$. In other words, these regions are the place of intense convective fluxes because they contain higher pollutant concentrations. This shows the importance of the contribution of the recirculation zones to the overall mass transport and the necessity for the turbulence model to simulate them properly.

Above the source, downstream of the building, the mean concentration decreases along the $\mathrm{x}$ direction. The gradient-diffusion hypothesis adopted with RANS leads to positive values for $\mathrm{Q}_{\mathrm{t}, \mathrm{x}} / \mathrm{Q}_{0}$, as can be seen in Figs. 11a,c,e. By contrast, LES predicts a negative streamwise turbulent mass flux in this zone (blue/dark gray zone in Fig. 11g), in qualitative agreement with the low Reynolds number DNS simulations by Rossi et al. [11]. It proves the ability of the present LES modeling to reproduce this so-called counter-gradient mechanism that acts in the streamwise direction. This, together with the smaller reattachment length, contributes to a shorter plume predicted by LES (Fig. 9e). In the vertical direction, the turbulent mass flux is predicted by LES with similar trend than RANS models, i.e. with a gradient-diffusion mechanism (Figs. 11b,d,f,h).

The observation of the contours of $\left|Q_{t, i} / Q_{c, i}\right|$ (not shown here) shows that for the $x$-direction the magnitude of the convective flux is generally one order of magnitude higher than the turbulent flux (except in the zones of very low streamwise velocity), proving the dominant role of convection as a mechanism of mass transport streamwise. In this direction, the turbulent mass transport plays a secondary role on the prediction accuracy of concentration. By contrast, convective and turbulent fluxes are of the same order of magnitude in the vertical direction. Turbulence even dominates convection, except on the centerline of the plume.

\section{Summary and conclusions}

Most previous studies on the prediction accuracy of RANS and LES have focused on the comparison of the resulting simulated and measured mean concentrations, rather than on the transport process itself. In this paper, a detailed analysis of the transport process of a pollutant in the turbulent wind flow patterns around isolated buildings has been presented, for two configurations with distinctive features in terms of the transport process. Apart from comparing mean concentrations, the relative influence of convective and turbulent fluxes in the transport process has been analyzed and the role of these fluxes in the prediction accuracy of RANS and LES has been clarified.

It was shown that LES is able to reproduce the counter-gradient mechanism that governs turbulent mass transfer in -and only in- the streamwise direction. This phenomenon was also pointed out by Rossi et al. [11] who performed DNS of dispersion around a cube with uniform inflow at $\mathrm{Re}=5,000$. They attributed this mechanism to the large-scale structures that emanate from the leading edge of the cube. In the present study, it was shown that the counter-gradient mechanism occurs not only for the cubic building with rooftop source immerged in a turbulent ABL flow, but also when the source is $1.5 \mathrm{H}$ high and a priori less affected by the building-generated turbulence. The very widespread gradient-diffusion hypothesis is therefore not valid in the $\mathrm{x}$-direction for the two cases considered here.

However, this erroneous prediction of the streamwise turbulent mass flux by the RANS models did not influence significantly the results since convection was shown to act as the dominant mechanism of mass transport in this direction -contrary to laterally and vertically. Hence, if the pollutant source is located outside of detachment regions or any notable zone of the flow-field that RANS models fail to reproduce (case 1), this class of models can predict fairly accurate convective fluxes around the source and, as a result, a fairly accurate concentration field. This requires correct parameterization of the turbulent fluxes via the turbulent Schmidt number, though.

When the influence of the building on the dispersion process is higher (case 2), the accuracy of LES is clearly better because this model computes more accurate convective fluxes, especially in separation regions on the roof and in the wake of the building. In such cases, modifications of $\mathrm{Sc}_{\mathrm{t}}$ will influence the spread of pollutant predicted by RANS models but cannot compensate for their deficiencies in terms of flow-field. The use of LES is recommended in this situation despite the increase in required computational time (RANS approximately seven times faster than LES for this case). 
Further research will focus on configurations where the role of turbulent mass transport is more important in the streamwise direction, in order to assess the need of more elaborate models for turbulent mass fluxes.

\section{Acknowledgements}

The numerical simulations reported in this paper were supported by the laboratory of the Unit Building Physics and Systems (BPS) of Eindhoven University of Technology.

\section{References}

[1] A. Walton, A.Y.S. Cheng, Large-eddy simulation of pollution dispersion in an urban street canyon-Part II: idealised canyon simulation, Atmos. Environ. 36 (2002) 3615-3627.

[2] S.M. Salim, R. Buccolieri, A. Chan, S. Di Sabatino, Numerical simulation of atmospheric pollutant dispersion in an urban street canyon: Comparison between RANS and LES, J. Wind Eng. Ind. Aerod. 99 (2011) 103-113.

[3] Y. Tominaga, T. Stathopoulos, CFD modeling of pollution dispersion in a street canyon: Comparison between LES and RANS, J. Wind Eng. Ind. Aerod. 99 (2011) 340-348.

[4] S.M. Salim, S.C. Cheah, A. Chan, Numerical simulation of dispersion in urban street canyons with avenuelike tree plantings: Comparison between RANS and LES, Build. Environ. 46 (2011) 1735-1746.

[5] C.-H. Chang, Computational fluid dynamics simulation of concentration distributions from a point source in the urban street canyons, J. Aerospace Eng. 19 (2006) 80-86.

[6] A. Dejoan, J.L. Santiago, A. Martilli, F. Martin, A. Pinelli, Comparison between Reynolds-Averaged Navier-Stokes computations for the MUST field experiment. Part II: Effects of incident wind angle deviation on the mean flow and plume dispersion, Bound.-Lay. Meteorol. 135 (2010) 133-150.

[7] Y. Tominaga, T. Stathopoulos, Numerical simulation of dispersion around an isolated cubic building: model evaluation of RANS and LES, Build. Environ. 45 (2010) 2231-2239.

[8] R. Yoshie, G. Jiang, T. Shirasawa, J. Chung, CFD simulations of gas dispersion around high-rise building in non-isothermal boundary layer, J. Wind Eng. Ind. Aerod. 99 (2011) 279-288.

[9] S.R. Hanna, M.J. Brown, F.E. Camelli, S.T. Chan, W.J. Coirier, O.R. Hansen, A.H. Huber, S. Kim, R.M. Reynolds, Detailed simulations of atmospheric flow and dispersion in downtown Manhattan - An application of five computational fluid dynamics models, B. Am. Meteorol. Soc. 87 (2006) 1713-1726.

[10] P. Gousseau, B. Blocken, T. Stathopoulos, G.J.F. Van Heijst, CFD simulation of near-field pollutant dispersion on a high-resolution grid: a case study by LES and RANS for a building group in downtown Montreal, Atmos. Environ. 45 (2011) 428-438.

[11] R. Rossi, D.A. Philips, G. Iaccarino, A numerical study of scalar dispersion downstream of a wall-mounted cube using direct simulations and algebraic flux models, Int. J. Heat Fluid Fl. 31 (2010) 805-819.

[12] A.H. Huber, W.H. Snyder, R.E. Lawson Jr., The effects of a squat building on short stack effluents - A wind tunnel study, U.S. Environmental Protection Agency report EPA-600/4-80-055, North Carolina, USA, 1980.

[13] W.-W. Li, R.N. Meroney, Gas dispersion near a cubical model building - Part I. Mean concentration measurements, J. Wind Eng. Ind. Aerod. 12 (1983) 15-33.

[14] W.P. Jones, B.E. Launder, The prediction of laminarization with a two-equation model of turbulence, Int. J. Heat Mass Tran. 15 (1972) 301-314.

[15] T.-H. Shih, W.W. Liou, A. Shabbir, Z. Yang, J. Zhu, A new k-e eddy-viscosity model for high Reynolds number turbulent flows, Comput. Fluids 24-3 (1995) 227-238.

[16] V. Yakhot, S.A. Orszag, S. Thangam, T.B. Gatski, C.G. Speziale, Development of turbulence models for shear flows by a double expansion technique, Phys. Fluids A4 (1992) 1510-1520.

[17] B.E. Launder, G.J. Reece, W. Rodi, Progress in the development of a Reynolds-stress turbulent closure, J. Fluid Mech. 68 (1975) 537-566.

[18] M.M. Gibson, B.E. Launder, Ground effects on pressure fluctuations in the atmospheric boundary layer, J. Fluid Mech. 86 (1978) 491-511.

[19] J. Smagorinsky, General circulation experiments with the primitive equations. I. The basic experiment, Mon. Weather Rev. 91 (1963) 99-164.

[20] M. Germano, U. Piomelli, P. Moin, W.H. Cabot, A dynamic subgrid-scale eddy viscosity model, Phys. Fluids A 3 (1991) 1760-1765.

[21] D.K. Lilly, A proposed modification of the Germano subgrid-scale closure method, Phys. Fluids A 4 (1992) 633-635.

[22] Fluent 6.3 User's Guide, Fluent Inc., Lebanon, 2006

[23] J. Kim, P. Moin, Application of a fractional step method to incompressible Navier-Stokes equations, J. Comput. Phys. 59 (1985) 308-323. 
[24] B. Blocken, T. Stathopoulos, J. Carmeliet, CFD simulation of the atmospheric boundary layer: wall function problems, Atmos. Environ. 41 (2007) 238-252.

[25] B. Blocken, J. Carmeliet, T. Stathopoulos, CFD evaluation of wind speed conditions in passages between parallel buildings-effect of wall-function roughness modifications for the atmospheric boundary layer flow, J. Wind Eng. Ind. Aerod. 95 (2007) 941-962.

[26] B.E. Launder, D.B. Spalding, The numerical computation of turbulent flows, Comp. Method. Appl. M. 3 (1974) 269-289.

[27] T. Cebeci, P. Bradshaw, Momentum transfer in boundary layers, Hemisphere Publishing Corporation, New York, 1977.

[28] Y. Tominaga, T. Stathopoulos, Turbulent Schmidt numbers for CFD analysis with various types of flowfield, Atmos. Environ. 41 (2007) 8091-8099.

[29] B. Blocken, T. Stathopoulos, P. Saathoff, X. Wang, Numerical evaluation of pollutant dispersion in the built environment: comparison between models and experiments, J. Wind Eng. Ind. Aerod. 96 (2008) $1817-$ 1831.

[30] P. Moin, K. Squires, W. Cabot, S. Lee, A dynamic subgrid-scale model for compressible turbulence and scalar transport, Phys. Fluids A3-11 (1991) 2746-2757.

[31] J. Franke, A. Hellsten, H. Schlünzen, B. Carissimo, Best practice guideline for the CFD simulation of flows in the urban environment, COST Action 732 (2007).

[32] Y. Tominaga, A. Mochida, R. Yoshie, H. Kataoka, T. Nozu, M. Yoshikawa, T. Shirasawa, AIJ guidelines for practical applications of CFD to pedestrian wind environment around buildings, J. Wind Eng. Ind. Aerod. 96 (2008) 1749-1761.

[33] T. van Hooff, B. Blocken, Coupled urban wind flow and indoor natural ventilation modelling on a highresolution grid: A case study for the Amsterdam ArenA stadium, Environ. Modell. Software 25 (2010) 5165 .

[34] E. Sergent, Vers une méthode de couplage entre la simulation des grandes échelles et les modèles statistiques, Thèse présentée devant l'Ecole Centrale de Lyon (2002).

[35] Y. Tominaga, A. Mochida, S. Murakami, S. Sawaki, Comparison of various revised k- $\varepsilon$ models and LES applied to flow around a high-rise building model with 1:1:2 shape placed within the surface boundary layer, J. Wind Eng. Ind. Aerod. 96 (2008) 389-411.

[36] S. Murakami, A. Mochida, Y. Hayashi, Examining the k- $\varepsilon$ model by means of a wind tunnel test and largeeddy simulation of the turbulence structure around a cube, J. Wind Eng. Ind. Aerod. 35 (1990) 87-100.

[37] W. Rodi, Comparison of LES and RANS calculations of the flow around bluff bodies, J. Wind Eng. Ind. Aerod. 69-71 (1997) 55-75. 

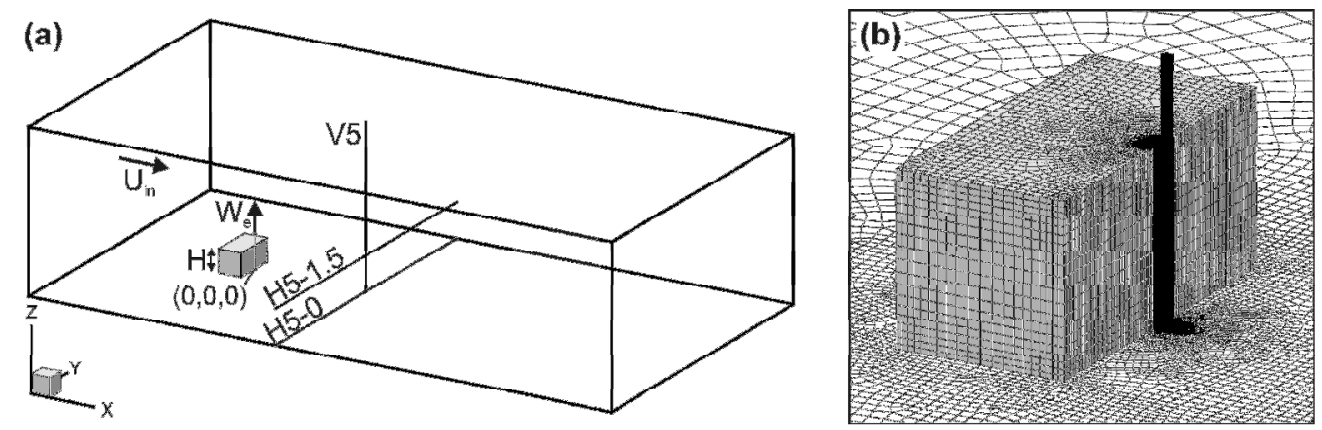

Figure 1. Case 1: (a) Domain, measurement lines for CFD validation and definition of parameters. Measurement lines: $\mathrm{H} 5-0$ corresponds to $\mathrm{x} / \mathrm{H}=5$ and $\mathrm{z} / \mathrm{H}=0.1 ; \mathrm{H} 5-1.5$ corresponds to $\mathrm{x} / \mathrm{H}=5$ and $\mathrm{z} / \mathrm{H}=1.5 ; \mathrm{V} 5$ corresponds to $\mathrm{x} / \mathrm{H}=5$ and $\mathrm{y} / \mathrm{H}=0$. (b) Grid on building, stack and ground surfaces (total number of cells: $1,450,960)$.

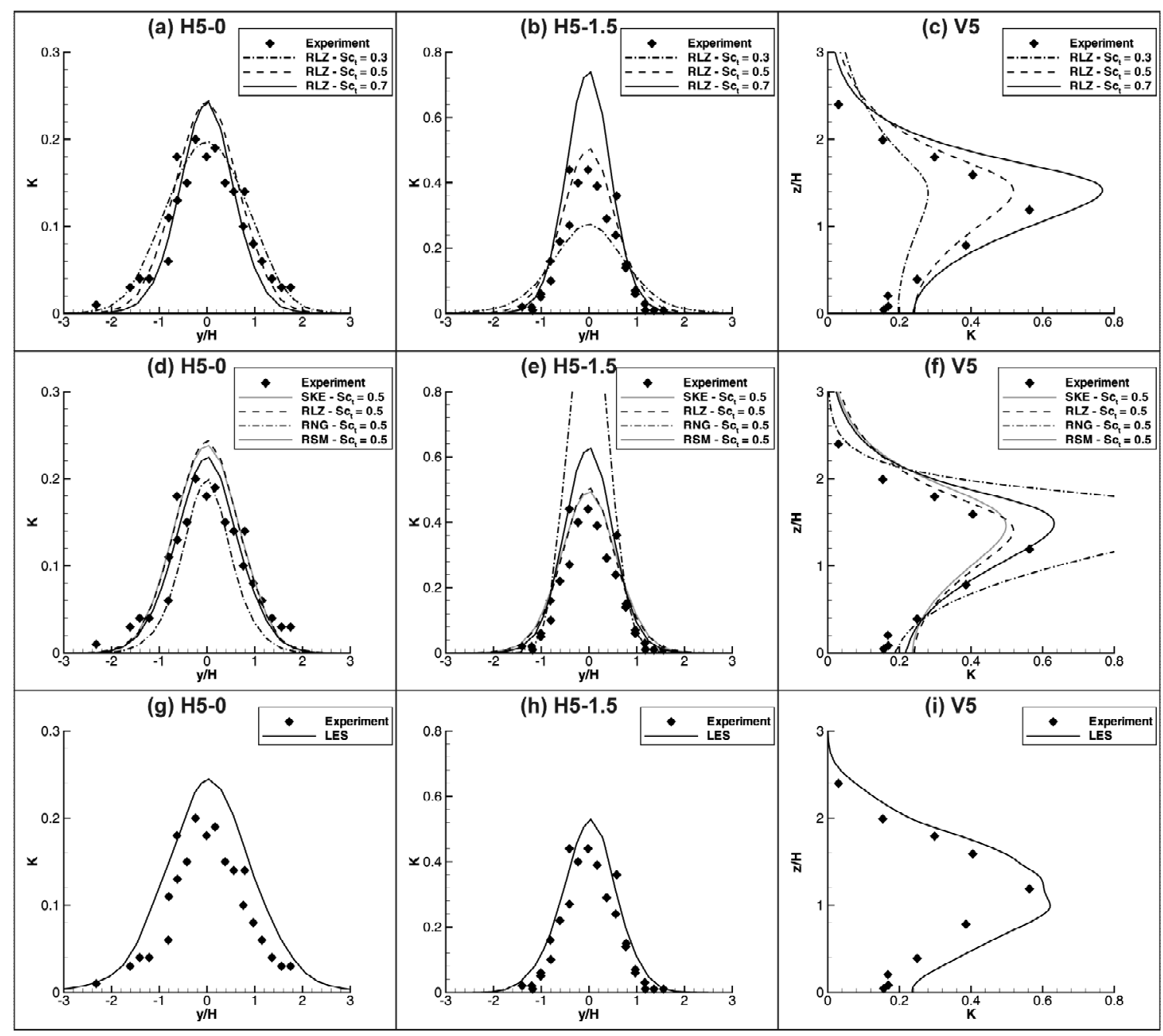

Figure 2. Profiles of K along H5-0 (left), H5-1.5 (middle) and V5 (right). (a,b,c) Influence of Sc $\mathrm{c}_{\mathrm{t}}$ value with RLZ. (d,e,f) Comparison between the four RANS models with $\mathrm{Sc}_{\mathrm{t}}=0.5$. (g,h,i) LES results. 

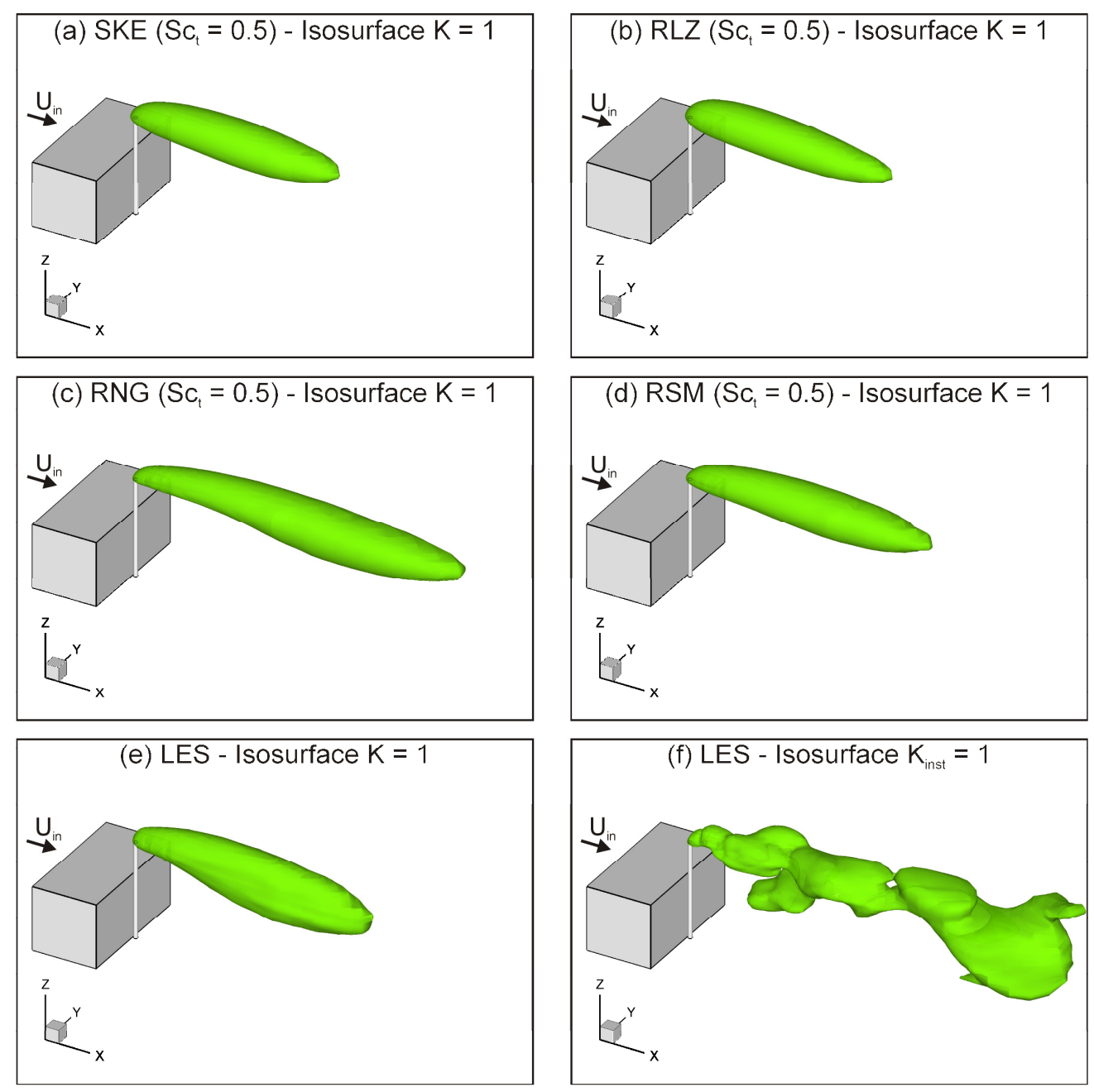

Figure 3. (a,b,c,d,e) Average plume shape obtained with the five turbulence models. (f) Instantaneous plume shape obtained with LES at $t^{*}=312$. 

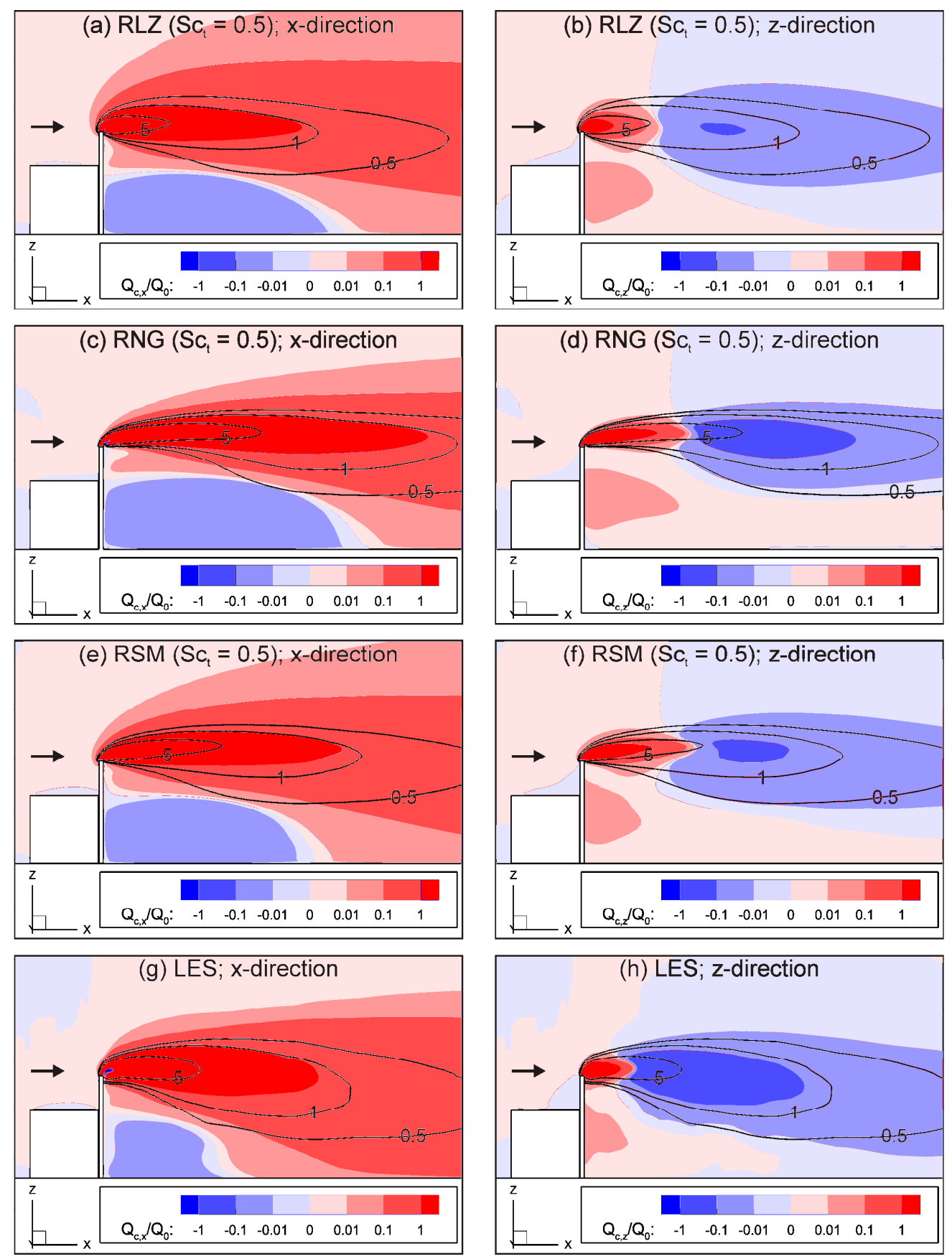

Figure 4. Streamwise (left; $\mathrm{Q}_{\mathrm{c}, \mathrm{x}} / \mathrm{Q}_{0}$ ) and vertical (right; $\mathrm{Q}_{\mathrm{c}, z} / \mathrm{Q}_{0}$ ) non-dimensional convective fluxes in the vertical mid-plane (y/H=0) obtained with (a,b) RLZ; (c,d) RNG; (e,f) RSM; and (g,h) LES. The isolines $\mathrm{K}=0.5 ; 1 ; 5$ are also shown. 

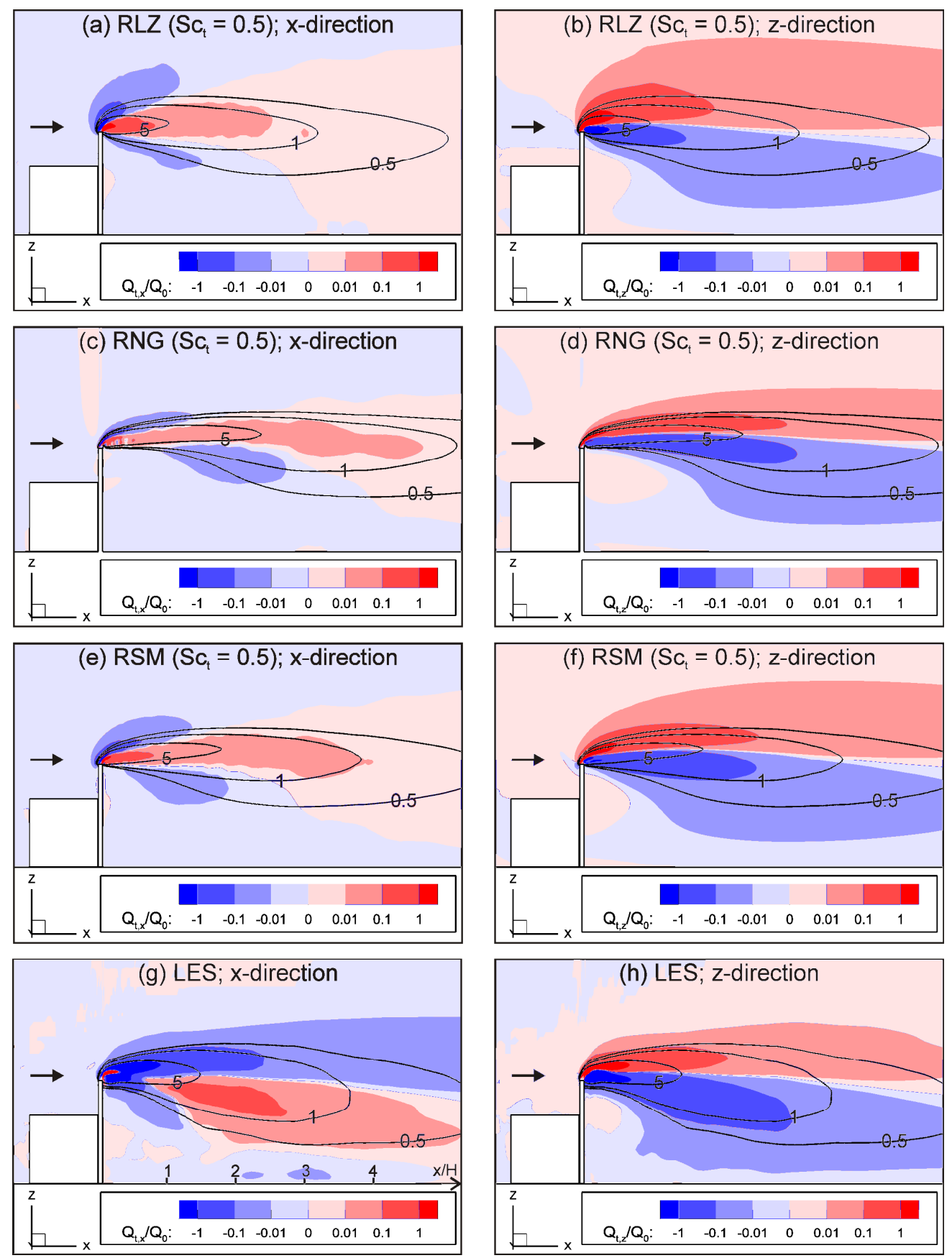

Figure 5. Streamwise (left; $\mathrm{Q}_{\mathrm{t}, \mathrm{x}} / \mathrm{Q}_{0}$ ) and vertical (right; $\mathrm{Q}_{\mathrm{t}, \mathrm{z}} / \mathrm{Q}_{0}$ ) non-dimensional turbulent fluxes in the vertical mid-plane (y/H=0) obtained with (a,b) RLZ; (c,d) RNG; (e,f) RSM; and (g,h) LES. The isolines $\mathrm{K}=0.5 ; 1 ; 5$ are also shown. 

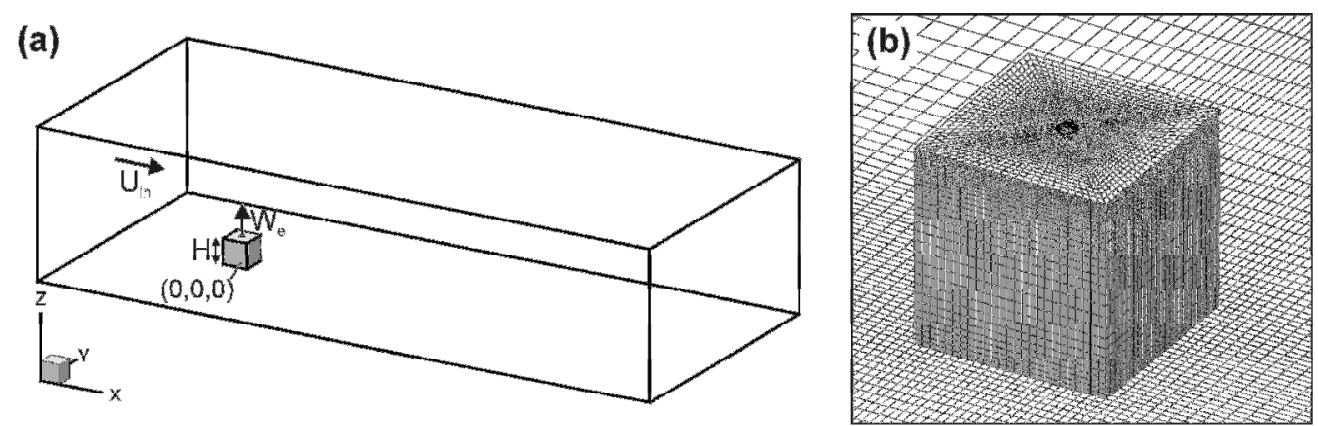

Figure 6. Case 2: (a) Domain and definition of parameters. (b) Grid on building and ground surfaces (total number of cells: $1,480,754$ ).

(a) Exp.

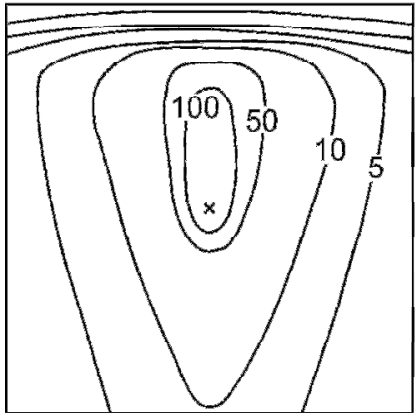

(d) RNG $\downarrow \quad\left(\mathrm{Sc}_{\mathrm{t}}=0.5\right)$

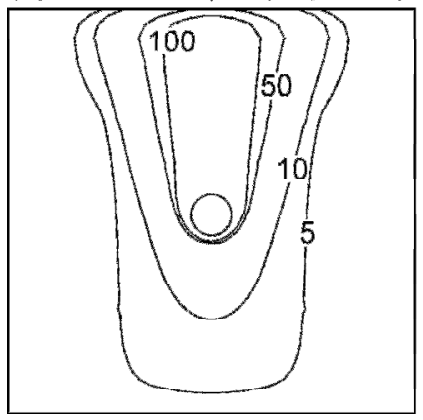

(b) SKE $\quad \downarrow \quad\left(S c_{t}=0.5\right)$

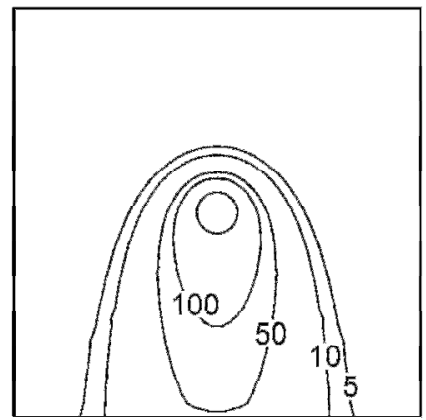

(c) RLZ

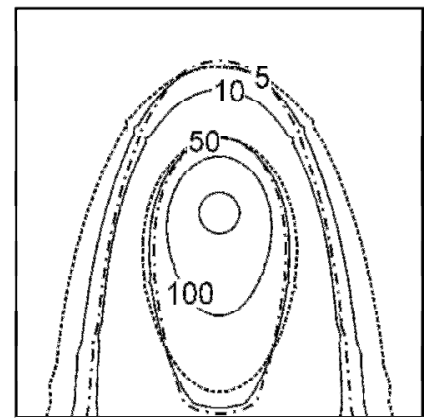

(e) RSM $\downarrow\left(\mathrm{Sc}_{\mathrm{t}}=0.5\right)$

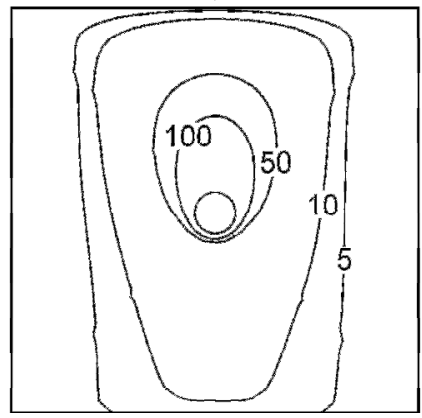

Figure 7. (a) Experimental and (b,c,d,e,f) numerical contours of $K$ on the roof. The arrows indicate the wind direction. The influence of $\mathrm{Sc}_{\mathrm{t}}$ is depicted in (c): - - : $\mathrm{Sc}_{\mathrm{t}}=0.3$; - : $\mathrm{Sc}_{\mathrm{t}}=0.5 ;---: \mathrm{Sc}_{\mathrm{t}}=0.7$. 
(a) Experiment

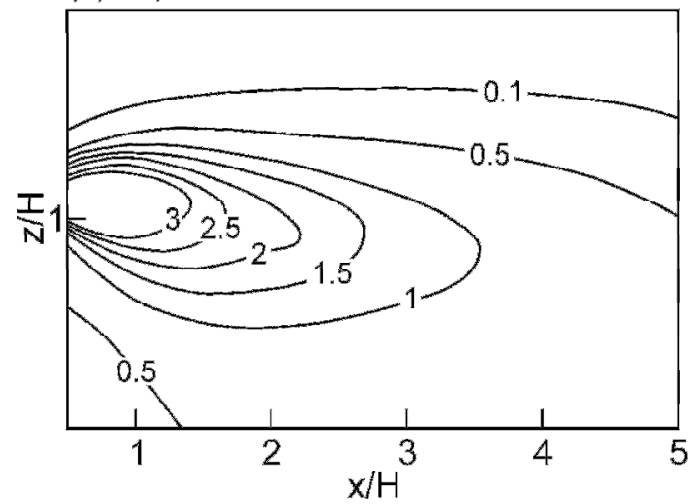

(c) RLZ

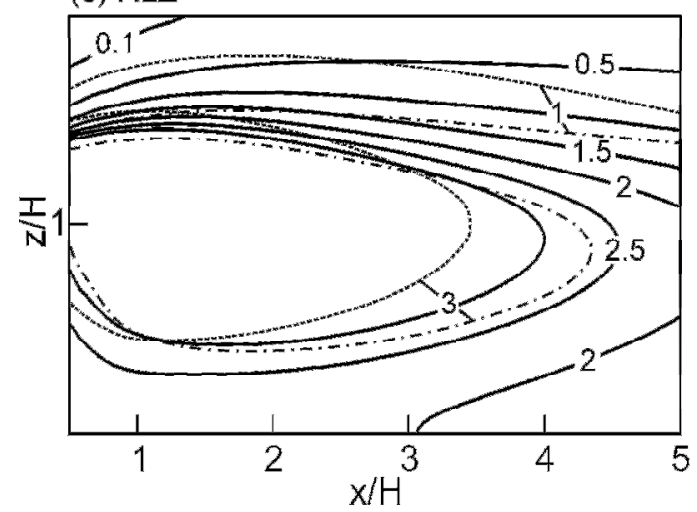

(e) $\operatorname{RSM}\left(\mathrm{Sc}_{\mathrm{i}}=0.5\right)$

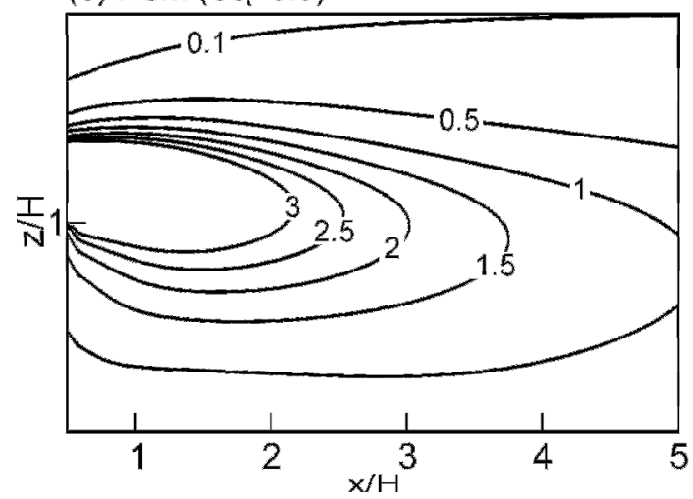

(b) $\mathrm{SKE}\left(\mathrm{Sc}_{\mathrm{n}}=0.5\right)$

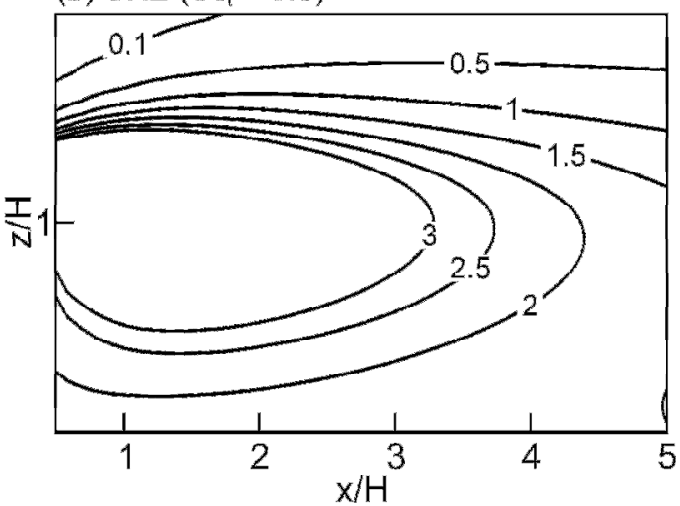

(d) RNG ( $\left.\mathrm{Sc}_{1}=0.5\right)$

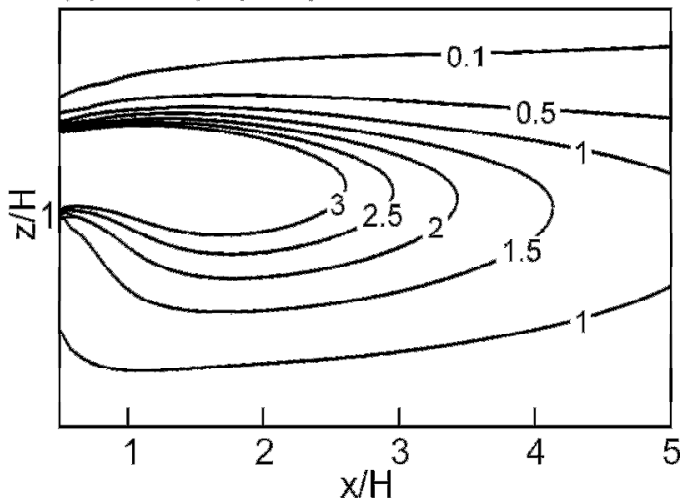

(f) LES

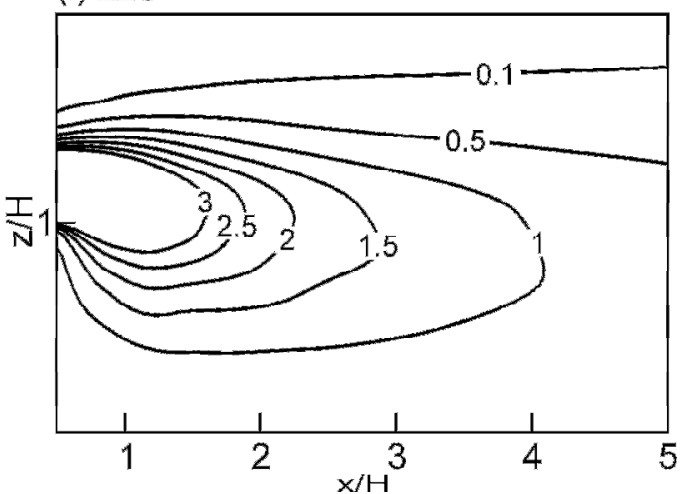

Figure 8. (a) Experimental and (b,c,d,e,f) numerical contours of $K$ in the wake of the building $(y / H=0)$. $\mathrm{x} / \mathrm{H}=0.5$ corresponds to the leeward facade of the building. The influence of $\mathrm{Sc}_{\mathrm{t}}$ is depicted in $(\mathrm{c}):---$ : $\mathrm{Sc}_{\mathrm{t}}=0.3 ;-: \mathrm{Sc}_{\mathrm{t}}=0.5 ;---: \mathrm{Sc}_{\mathrm{t}}=0.7$. 

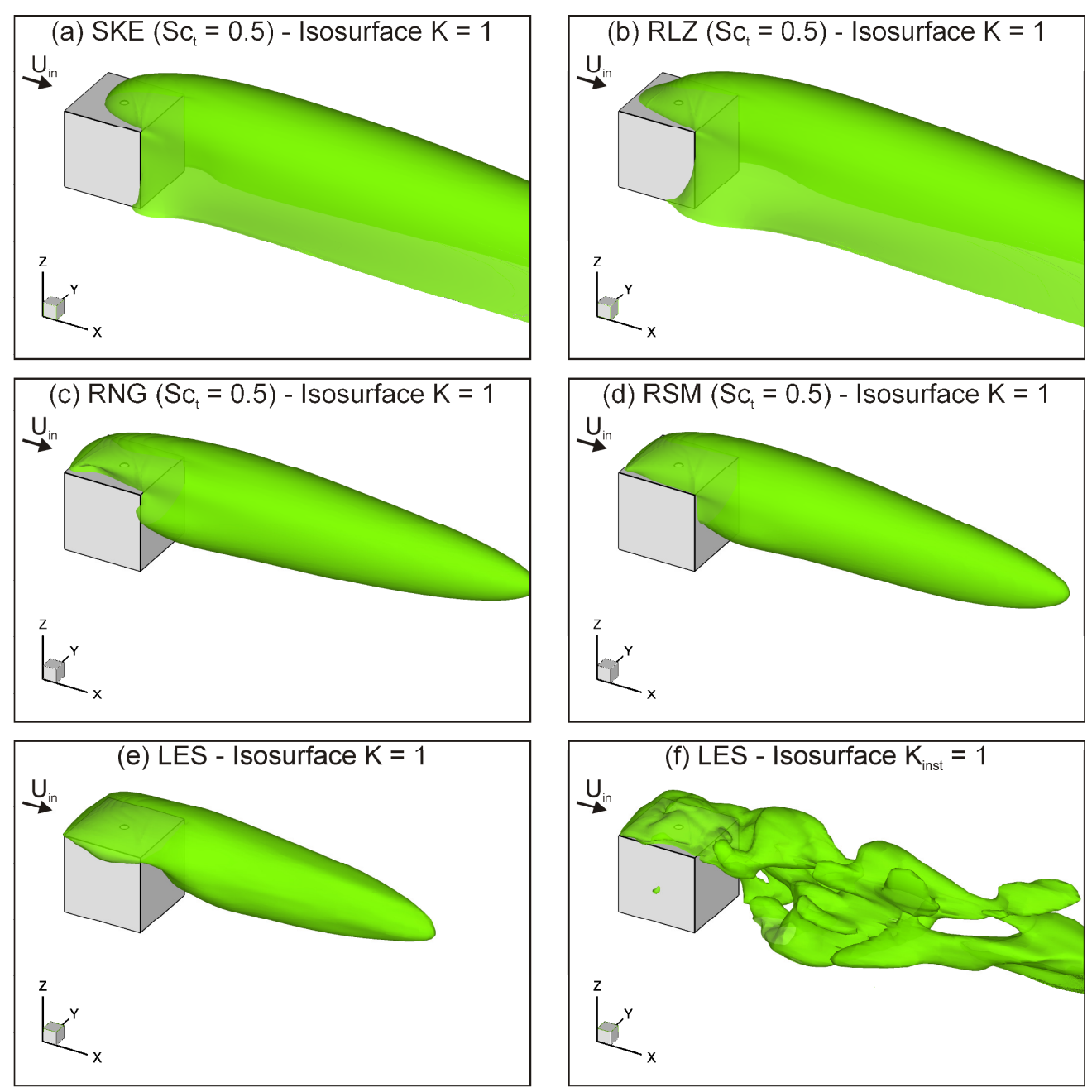

Figure 9. (a,b,c,d,e) Average plume shape obtained with the five turbulence models. (f) Instantaneous plume shape obtained with LES at $t^{*}=594$. 

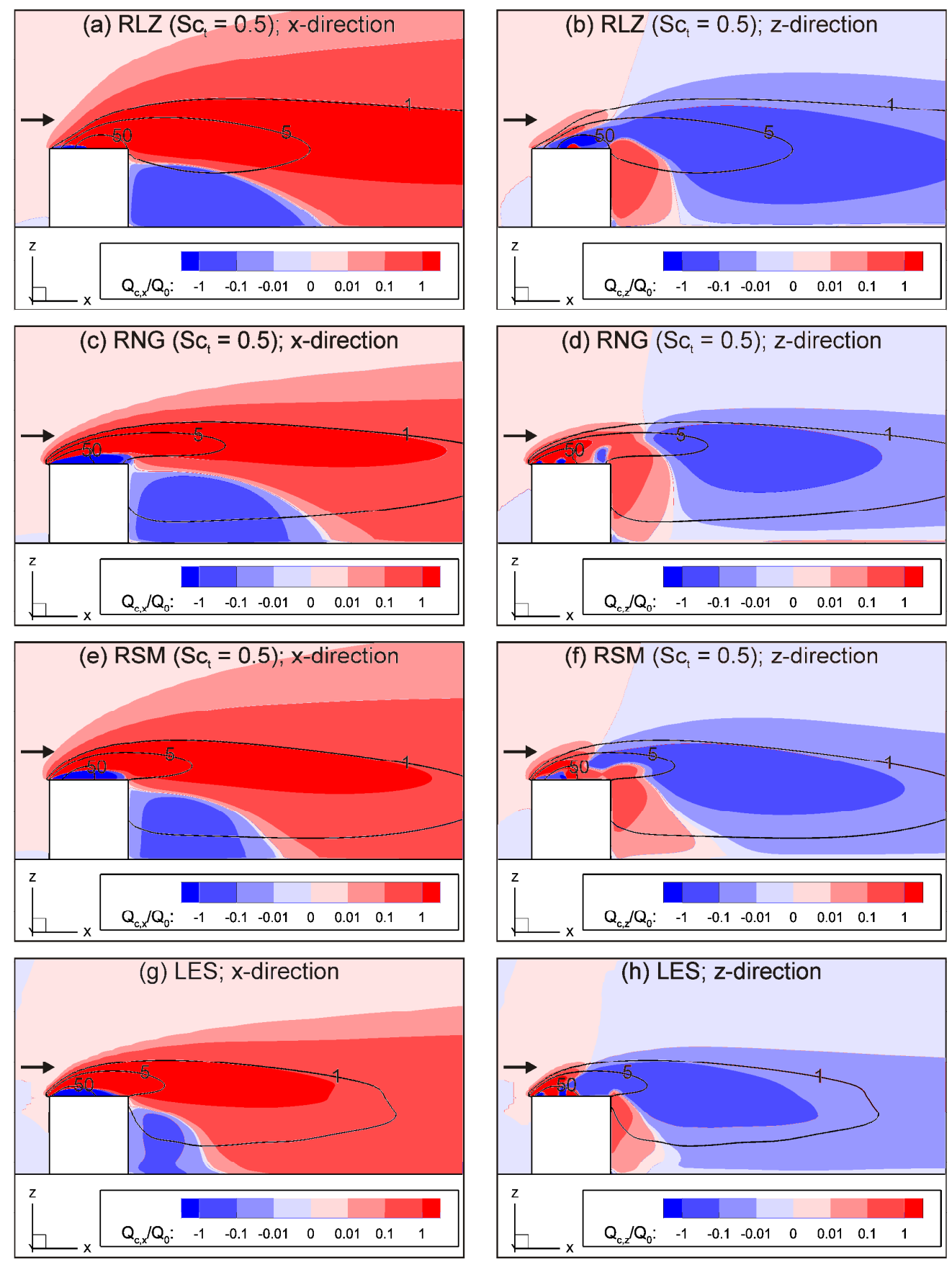

(d) RNG (Sct $=0.5)$; z-direction
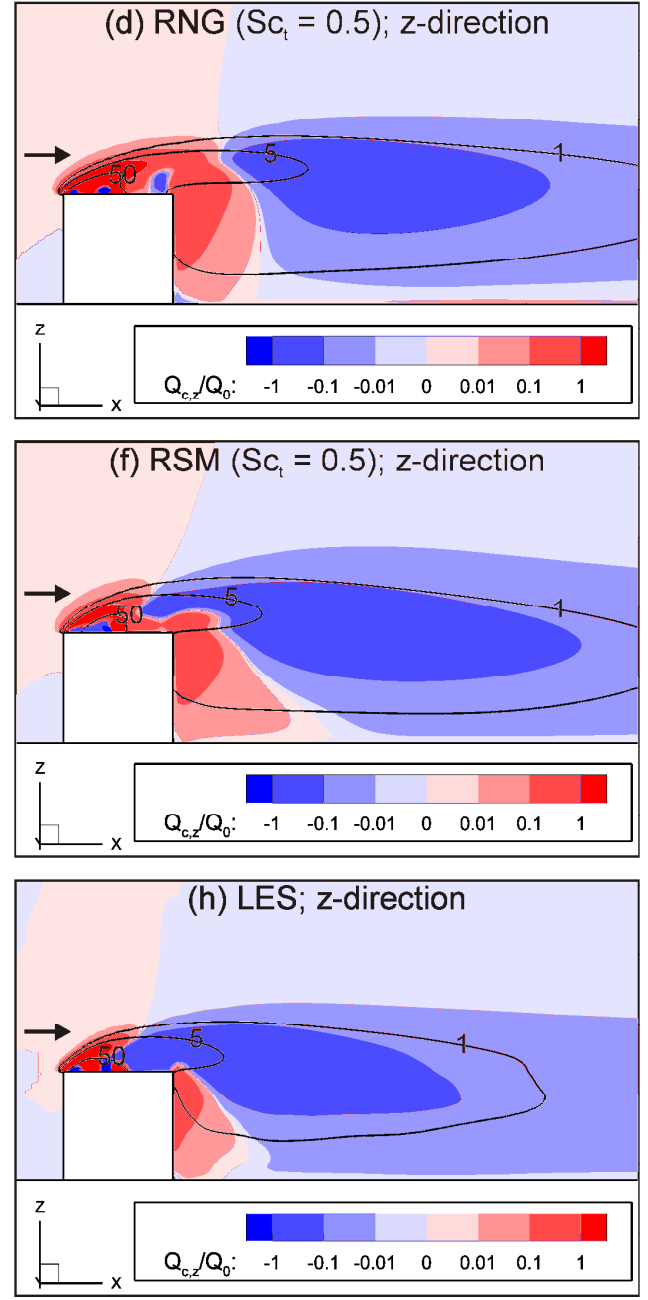

Figure 10. Streamwise (left; $\mathrm{Q}_{c, x} / \mathrm{Q}_{0}$ ) and vertical (right; $\mathrm{Q}_{\mathrm{c}, \mathrm{Z}} / \mathrm{Q}_{0}$ ) non-dimensional convective fluxes in the vertical mid-plane (y/H=0) obtained with (a,b) RLZ; (c,d) RNG; (e,f) RSM; and (g,h) LES. The isolines $\mathrm{K}=1 ; 5 ; 50$ are also shown. 

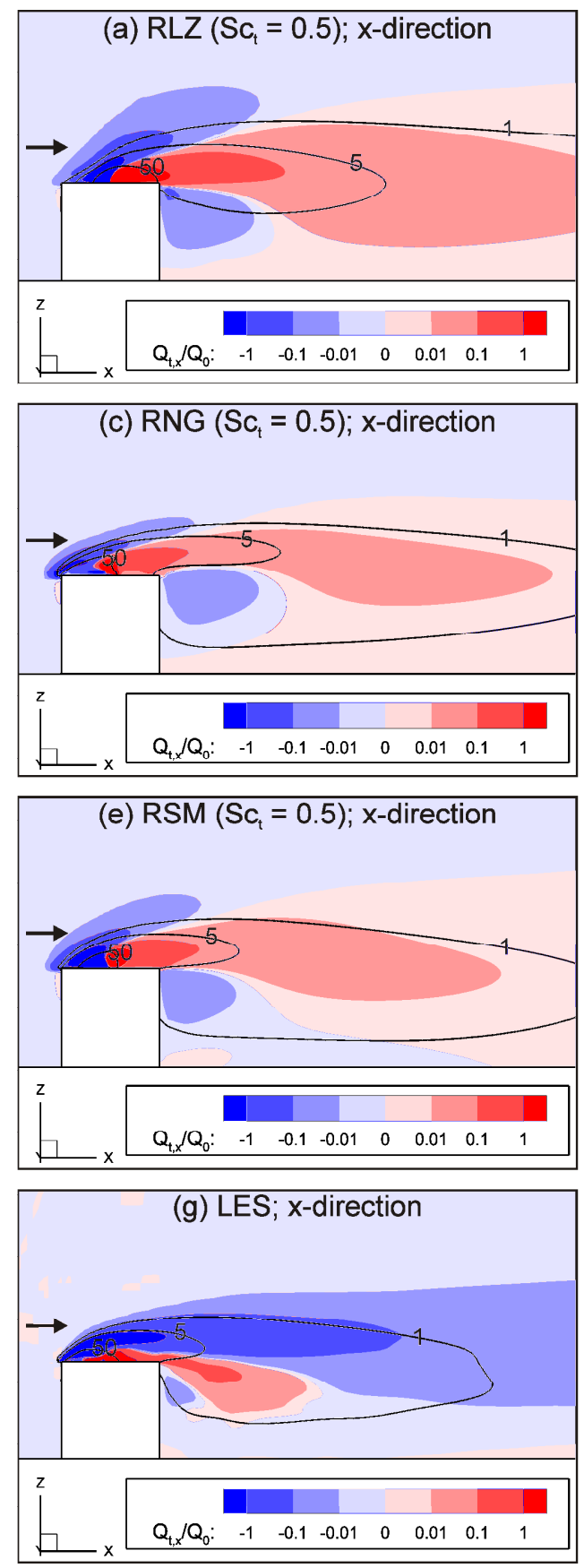

Figure 11. Streamwise (left; $\mathrm{Q}_{\mathrm{t}, \mathrm{x}} / \mathrm{Q}_{0}$ ) and vertical (right; $\mathrm{Q}_{\mathrm{t}, \mathrm{z}} / \mathrm{Q}_{0}$ ) non-dimensional turbulent fluxes in

the vertical mid-plane (y/H=0) obtained with (a,b) RLZ; (c,d) RNG; (e,f) RSM; and (g,h) LES. The isolines $\mathrm{K}=1 ; 5 ; 50$ are also shown.

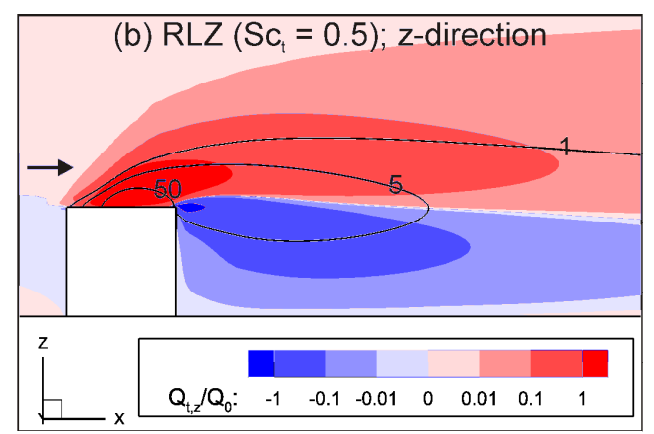

(d) RNG ( $\left.\mathrm{Sc}_{1}=0.5\right)$; z-direction
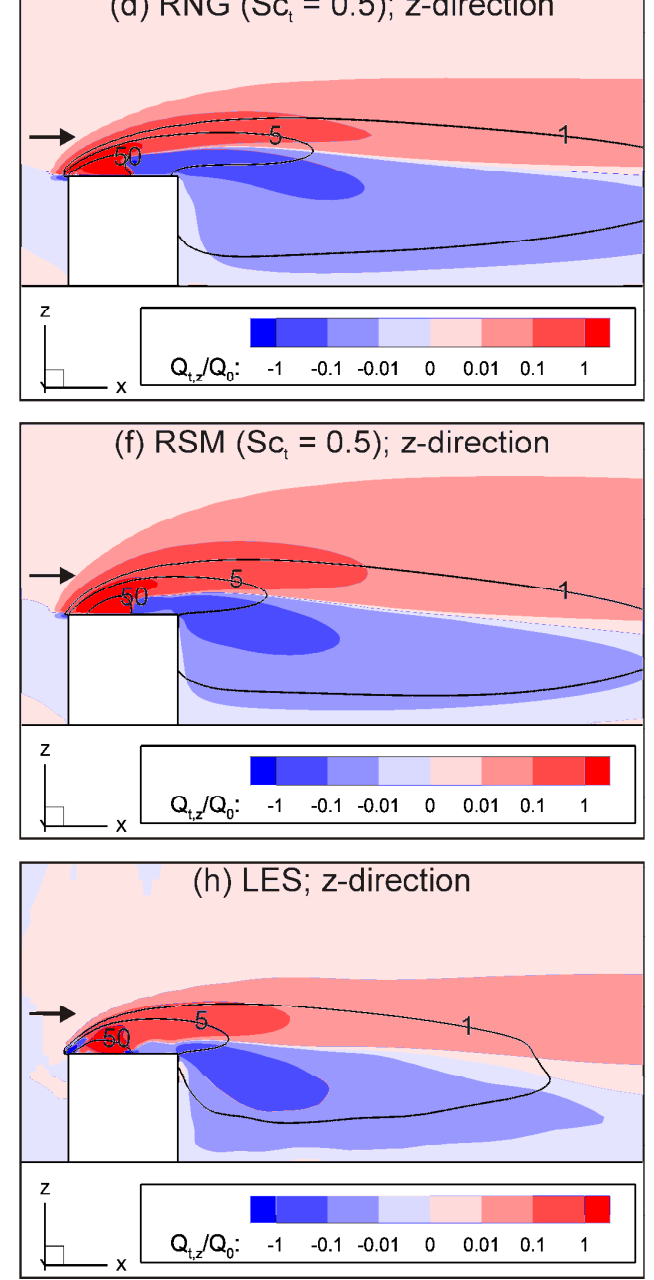